\title{
C-space approach to tool-path generation for sculptured surface machining
}

\author{
Byoung K. Choi \\ IE Dept., KAIST, 373-I Kusong-dong, Yusong-gu, Taejon 305-701, Korea (Fax:+82-42-861- \\ 9195; Phone:+82-42-869-3115; E-mail: bkchoi@bezier.kaist.ac.kr)
}

Key words: C-space, sculptured surface machining, tool-path

Abstract: Presented in the paper is a new approach to tool-path generation for sculptured surface machining. In the proposed $C$-space approach, the geometric data describing the design-surface, stock-surface and tool shape are transformed into $C$-space elements, and then, all the tool-path generation decisions are made in the configuration space ( $\mathrm{C}$-space). The $\mathrm{C}$-space approach provides a number of distinctive features suitable for sculptured surface machining, including: 1) gouge-free tool-paths; 2) uncut handling; 3) balanced cuttingload; 4) smooth cutter movement; 5) collision-free tool-path.

\section{INTRODUCTION}

Sculptured surface machining (SSM) is an important technology in modern manufacturing industry, especially for automotive and consumerelectronics industries, as many products are designed with sculptured surface to enhance their aesthetic appeal as well as to meet functional requirements. Following five items are considered to be critical factors for a successful SSM.

(1) Gouge-free tool path: Gouge refers to the over-cutting of the workpiece during the cutting mode ( $\mathrm{G} 01$ mode). A concave-gouge may occur at a $\mathrm{CL}$-point in a concave region (Figure 1-a), while a convex-gouge may occur on a CL-line in a convex region (Figure 1-b).

(2) Uncut handling: The term uncut refers to the under-cutting of the 
workpiece: a concave-uncut occurs at a concave region when the cutter is too large to fit into the concave region without a concave-gouge (Figure 1-c); a convex-uncut, which is better known as a cusp, occurs between adjacent CL-paths.

(3) Balanced cutting-load: There would be no time to adjust for an abrupt jump in the chip-load, resulting in cutter breakage. The fluctuations in chip-loads should be estimated a priori so that feedrate be adjusted adaptively to maintain a smooth cutting-load (to avoid chatter).

(4) Smooth cutter movement: Sharp turns in cutter motion would push the cutter off the course, leaving tool-marks on the machined surface and resulting in out-of-tolerance areas.

(5) Collision-free tool path: Collision may be categorized either "rapidmove" or "cutting-move" type. The former refers to accidental contacts between tool elements and work-piece during the traverse mode (G00 mode), while the latter refers to contacts between non-cutting toolelements (dead-center, shank, holder) and work-piece during cutting

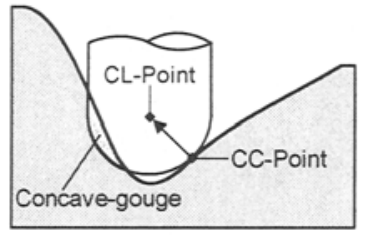

(a) Concave-gouge

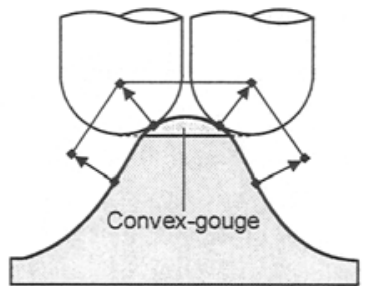

(b) Convex-gouge

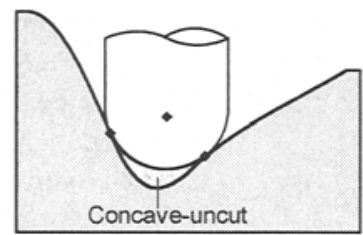

(c) Concave-uncut

mode (G01/G02 mode).

Figure 1 Gouging and Uncut

According to how CL-points are obtained, tool-path generation methods may be categorized either as CC-point approach or as direct positioning approach. These conventional approaches are suitable for gougefree tool path generation, but the rest of the requirements can hardly be achieved by these approaches [20]. In this paper we present a new approach to SSM, called C-space approach, in which the geometric data describing the design-surface and stock-surface as well as tool shape are transformed into $\mathrm{C}$-space elements, and then, all the tool-path generation decisions are made in the configuration space (C-space). The $\mathrm{C}$-space approach provides a number of distinctive features suitable for SSM.

This paper is arranged as follows: the next section contains a description of the $\mathrm{C}$-space approach to 3-axis machining, and C-space for 5axis machining is given in the third section. Some implementation issues and preliminary results are presented in the fourth section. Finally concluding remarks and future research directions are given in the fifth section. 
The concept of C-space has long been applied to a range of spatial planning problems in connection with the automatic planning of manipulator transfer movements $[14,15]$. The C-space idea is easily applied to the (3axis) tool-path planning problem if the cutting tool is treated as the moving object and the work-piece plays the role of the obstacle.

\subsection{C-space for 3-axis machining}

The configuration of a 3-axis NC machine system is specified by a 3D position vector (denoting the positions of the $\mathrm{x}-, \mathrm{y}-$, and $\mathrm{z}$-axis), while its $\mathrm{C}$ space is given by the volume $\left(\mathrm{V}_{\mathrm{NC}}\right)$ in a Cartesian space within the reach of the cutting tool. For SSM, we need to have two types of safe C-space: 1) Free C-space denoting the free-of-collision space; 2) Machining C-space denoting the machining space. Now lets consider the two CL-surfaces, one for the design surface and the other for the stock surface, as depicted in Figure 2:

(1) $\mathrm{S}_{\mathrm{D}}=$ design CL-surface (CL-surface for the design surface).

(2) $\mathrm{S}_{\mathrm{S}}=$ stock CL-surface (CL-surface for the stock surface).

Then, as shown in Figure 2, the two CL-surfaces would divide the entire Cspace of the $\mathrm{NC}$ machine into three disjoint $\mathrm{C}$-spaces as follows:

1. $\mathrm{V}_{\mathrm{F}}=$ free $\mathrm{C}$-space (space above $\mathrm{S}_{\mathrm{S}}$ exclusive) ;

2. $\mathrm{V}_{\mathrm{M}}=$ machining $\mathrm{C}$-space (space between $\mathrm{S}_{\mathrm{S}}$ and $\mathrm{S}_{\mathrm{D}}$ inclusive);

3. $\mathrm{V}_{\mathrm{G}}=$ gouging $\mathrm{C}$-space (space below $\mathrm{S}_{\mathrm{D}}$ exclusive).

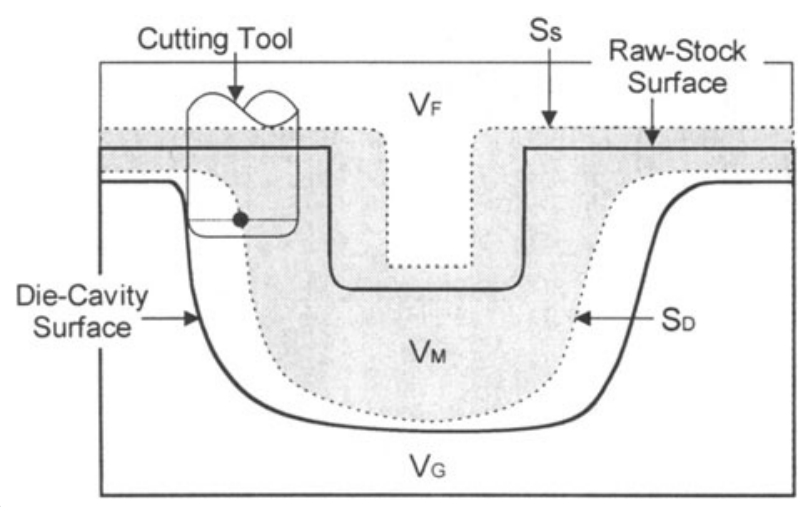

Figure 2 Construction of C-space for 3-axis Machining

In die \& mold machining, we are given a set of geometric information regarding the design-surface of the die, its stock-surface, uncut-allowance, cutter shape, etc. Then, C-space Elements $=\left\{\mathrm{S}_{\mathrm{S}}, \mathrm{S}_{\mathrm{D}}, \mathrm{V}_{\mathrm{F}}, \mathrm{V}_{\mathrm{M}}, \mathrm{V}_{\mathrm{G}}\right\}$ are 
obtained such that the volume-type elements satisfy $V_{\mathrm{NC}}=\mathrm{V}_{\mathrm{F}} \cup \mathrm{V}_{\mathrm{M}} \cup \mathrm{V}_{\mathrm{G}}$ with $\varnothing=\mathrm{V}_{\mathrm{F}} \cap \mathrm{V}_{\mathrm{M}} \cap \mathrm{V}_{\mathrm{G}}$. In other words, the overall procedure for obtaining the $\mathrm{C}$-space elements is as follows:

(1) Stock CL-surface $\left(\mathrm{S}_{\mathrm{S}}\right)$ is obtained from the stock surface..

(2) Design CL-surface $\left(S_{D}\right)$ is obtained from the design surface taking into account the uncut-allowance.

(3) The $C$-space volume elements $\left(V_{F}, V_{M}, V_{G}\right)$ are obtained from the CLsurfaces.

The above C-space elements contain all the geometric information necessary for generating tool-paths. Furthermore, the C-space approach possesses the following properties [20].

1. There always exists a unique CL-surface for a 3-axis endmill.

2. The CL-surface for a 3 -axis endmill is equivalent to the inverse tooloffset (ITO) surface (Figure 3).

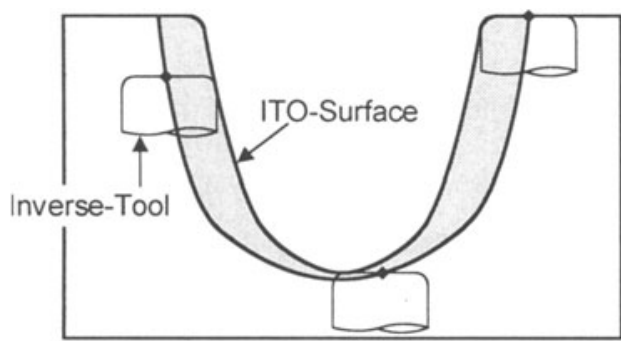

Figure 3 Inverse Tool-offset Surface (ITO-surface)

Property 1 asserts that the C-space approach will always produce a unique and valid CL-surface, while Property 2 provides a robust method for generating the CL-surface. The ITO-surface is defined as the envelope of the cutter swept volumes obtained by sweeping the inverse cutter over the entire surface with its reference point kept on the surface [10]. The inverse offset is exactly the same as the 'Minkowski sum' of the surface and the inverse cutter [21].

\subsection{Characteristics of the 3-axis C-space}

Recall that the requirements for successful SSM are gouge-free, uncut handling, balanced cutting-load, smooth cutter movement and collision-free. Given in the following are brief descriptions of how the requirements might be handled, at least partially, with the C-space method:

(1) Gouge-free machining: There will be no gouging if all the cuttingmoves are kept out of the gouging $C$-space $\mathrm{V}_{\mathrm{G}}$.

(2) Uncut handling: If the ball-endmill CL-surface $S_{D}$ is G1-continuous[21], there will be no concave-uncuts when the part is machined with the NC- 
data obtained from the CL-surface. Otherwise, clean-up cutting operations may be needed along the sharp edges of the CL-surface.

(3) Balanced cutting-load: In ball-endmilling, the chip-loads can be estimated from the differential properties of the design CL-surface $\left(\mathrm{S}_{\mathrm{D}}\right)$ when the cutting-depth is uniform: Chip-loads are high in concave regions and low in convex regions. So cutting-loads may be smoothed out by adjusting feedrates (increased at convex regions and decreased at concave regions) according to the radii of curvature of $S_{D}$.

(4) Smooth cutter movement: It is always possible to generate smooth toolpaths by tracing out smooth curves on the CL-surface $\mathrm{S}_{\mathrm{D}}$.

(5) Collision avoidance: The $\mathrm{C}$-space method allows a straightforward mechanism for preventing collisions (cutting-move collision and rapidmove collision). This point will be elaborated further in the next subsections.

\subsection{Cutting-move collision avoidance}

As shown in Figure 4-a, an endmill assembly consists of four elements: cutting-edge, dead-center, shank and holder. Actual cutting actions take place only at the cutting-edge. The dead-center is the center region of the endmill-bottom which has no cutting capability. If a non-cutting element is in contact with the workpiece during a machining operation, we have a cutting-move collision. Thus, there are three types of cutting-move collision: dead-center collision, shank-collision and holder-collision.

It should be observed that a dead-center collision may occur during a downward-milling only, while a shank-collision may occur during a upward-milling. On the other hand, a holder collision can occur in both downward milling and upward milling. Now, as depicted in Figure 4-b, define an "inverse" tool (IT) for each element of the endmill-assembly: cutting-edge IT, dead center IT, shank IT and holder IT. Note that we use the same reference-point $C$ in all the inverse-tools. The next step is to generate ITO (inverse tool offset) surfaces as follows:

(1)Cutting-edge ITO-surface: design CL-surface $\left(S_{D}\right)$ for the cutting-edge IT.

(2) Dead-center ITO-surface: stock CL-surface (Ss) for the dead center IT.

(3) Shank ITO-surface: stock CL-surface (Ss) for the shank IT.

(4) Holder ITO-surface: stock CL-surface (Ss) for the holder IT.

Then, a necessary condition for a holder-collision may be expressed as "there exists a region where the holder ITO-surface is higher than the cutting-edge ITO-surface", as indicated in Figure 4-c. Similarly, a necessary condition for a shank-collision (dead-center collision) may be expressed as "there exists a region where the shank ITO-surface (dead-center ITO- 
surface) is higher than the cutting-edge ITO-surface when the endmill is moving upward (downward)".

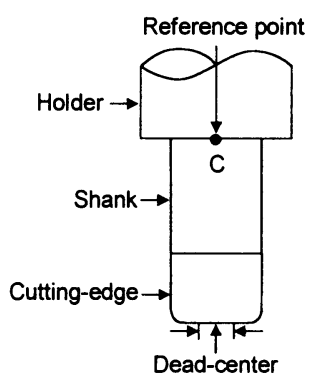

(a) Endmill-assembly

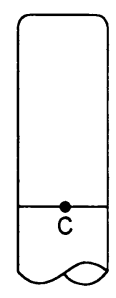

Cutting-edge

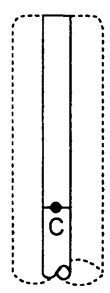

Dead-center

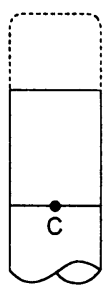

Shank

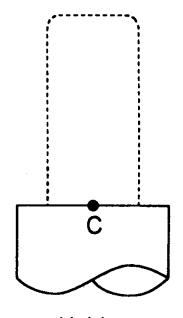

Holder

(b) Inverse-tool

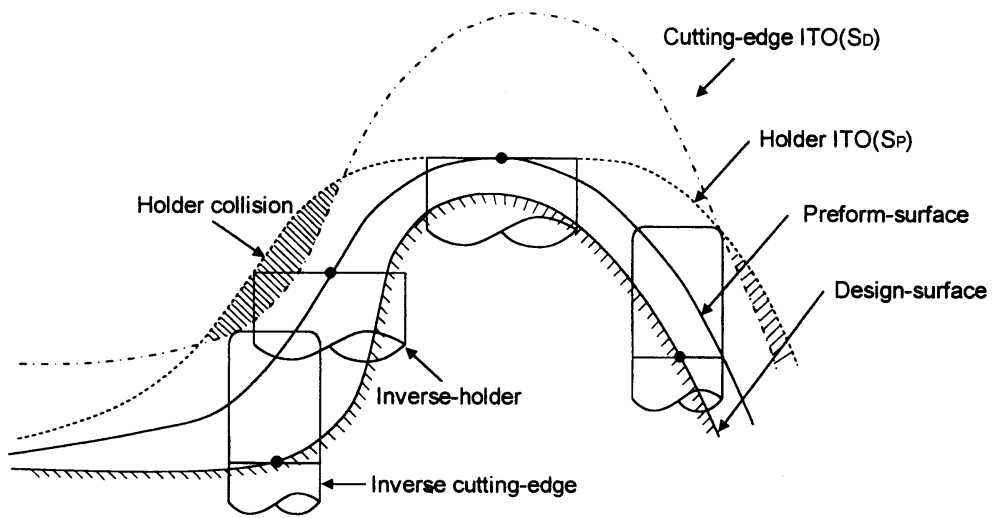

(c) Holder-collision check

Figure 4 Collision detection

\subsection{Rapid-move collision avoidance}

Rapid-move collisions can be avoided by preventing rapid-moves from entering the machining $\mathrm{C}$-space volume $\mathrm{V}_{\mathrm{M}}$. This is equivalent to confining the rapid-moves above the stock CL-surface Ss.

\section{C-SPACE APPROACH TO 5-AXIS MACHINING}

Discussed in this section are methods of applying the C-space concept to the gouging- and collision-avoidance problems in 5-axis machining. The usefulness of the $\mathrm{C}$-space method is rather limited in 5-axis machining, but there are certain cases where the $\mathrm{C}$-space concept can be 
used quite successfully. The C-space methods described in earlier sections are easily adaptable to the 5-axis cases of ball-endmilling and side-milling. In particular, the offset surfaces can be generated by inverse tool-offset method. The problem then becomes one of making sure that the center-line of the tool does not interfere with the offset surface. Unfortunately, however, the C-space method is not easily applied to 5-axis machining with a flat or round-endmill cutter mainly because the concept of CL-surface is not clearly defined in this case. Thus, for 5-axis machining, we introduce the concepts of "position" C-space and "orientation" C-space.

\subsection{Position C-space methods for 5-axis machining}

For a given part surface $\mathrm{S}_{\mathrm{P}}$, the position $\mathrm{C}$-space of a 5-axis roundendmill is constructed as follows. First, construct two offset surfaces of $S_{P}$ for a round-endmill of cutter-radius $\rho$ and corner-radius $\chi$ as follows (See Figure 5-a):

- $S_{\rho}^{o}=\rho$-offset surface: $S_{\mathrm{P}}$ is offset with an offset distance of $\rho$.

- $S_{\chi}^{o}=\chi$-offset surface: $S_{\mathrm{P}}$ is offset with an offset distance of $\chi$.

Second, the CL volume $\mathrm{V}_{\mathrm{CL}}$ bounded by the two offset surfaces $S_{\rho}^{o}$ and $S_{\chi}^{o}$ is defined as shown in Figure 5-a. Note that $S_{\chi}^{o} \equiv \mathrm{S}_{\mathrm{P}}$ for a flatendmill and $S_{\chi}^{o} \equiv S_{\rho}^{o}$ for a ball-endmill or a side-milling cutter. Third, the cutting tool is shrunk to a line segment called a "tool-axis line" as depicted in Figure 5-b.

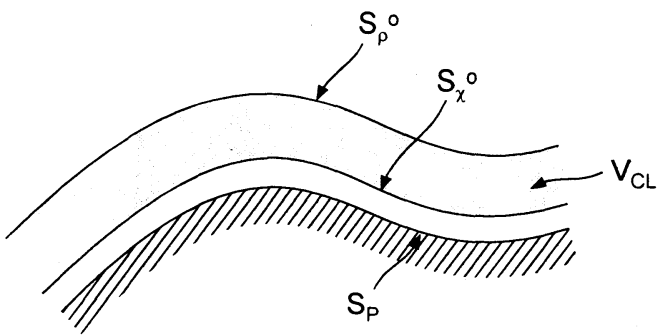

(a)

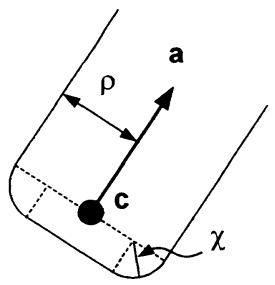

(b)

Figure 5 Position C-space Construction

The equation $\lambda(\mathbf{c}, \mathbf{a})$ of the tool-axis line is given by: $\lambda(\mathbf{c}, \mathbf{a}): \mathbf{r}(t)=\mathbf{c}$ $+t \cdot \mathbf{a}$ for $0 \leq t \leq \mathrm{L}$, where $\mathrm{L}$ is the length of the tool. With the position Cspace as given in Figure 5, the following statements can be made concerning the validity of the CL-data $C_{L}=(\mathbf{c}, \mathbf{a})$ : 
(1) The CL-point of an endmill is confined within the CL volume, namely, c $\in \mathrm{V}_{\mathrm{CL}}$.

(2) There should be one and only one "intersection" between $\lambda(\mathbf{c}, \mathbf{a})$ and $S_{\rho}^{o}$. The first statement is related to do with gouging avoidance but could not guarantee it, while cutter-collisions are avoided by the second statement in which "intersection" includes a tangential contact as well as a point contact. For both ball-endmilling and side-milling, the CL-volume reduces to the $\rho$ offset surface. Thus, for ball-endmilling, the above statements have to be changed to:

(1) The CL-point should be on the $\rho$-offset surface, namely, $\mathbf{c} \in S_{\rho}^{o}$.

(2) The tool-axis line $\lambda(\mathbf{c}, \mathbf{a})$ makes a single point contact with $S_{\rho}^{o^{\rho}}$.

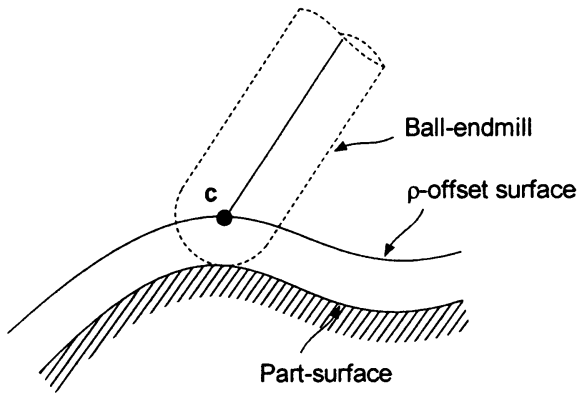

(a)

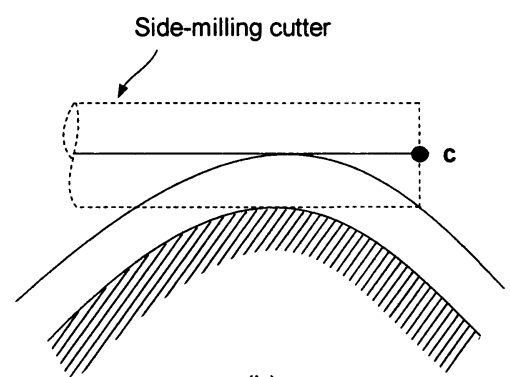

(b)

Figure 6 Position C-space method

These restrictions now guarantee gouging avoidance in ball-endmilling. For side-milling, on the other hand, the above statements reduce to the following statement:

(1) The tool-axis line $\lambda(\mathbf{c}, \mathbf{a})$ makes a tangential contact with $S_{\rho}^{o}$.

As shown in Figure 6, the tool-axis line of a ball-endmill makes a point contact with the $\rho$-offset surface, while the tool-axis line of a side-milling cutter makes a tangential contact with the $\rho$-offset surface.

\subsection{Orientation C-space methods for 5-axis machining}

For a given CC-data, its CL-data $C_{L}=(\mathbf{c}, \mathbf{a})$ is uniquely determined once its orientation $\mathrm{O}=(\alpha, \beta)$ is fixed. Thus, the $C$-space concept can be applied to the cutter orientation $\mathrm{O}$ instead of to the tool-axis vector a (It is not easy to define a $\mathrm{C}$-space for a). For a given CC-path $\left\{\mathrm{p}_{\mathrm{j}}\right\}$, we can construct a feasible orientation area $\Phi$ for each CC-point $p_{j}$ on the $\alpha \beta$-plane as shown in Figure 7 . If the cutter-orientation angles are within the feasible 
orientation area, i.e. $(\alpha, \beta) \in \Phi$, then the CL-data is free from "errors" (such as gouging, collision and joint limit-over).

Let $\gamma$ denote the arc-length of the CC-path and compute the feasible orientation area for each value of $\gamma$, which may be denoted as $\Phi(\gamma)$. Then we can define a "feasible orientation volume" from $\Phi(\gamma)$ in the 3D-coordinate system formed by $\alpha, \beta$ and $\gamma$. The feasible orientation volume in the $\alpha \beta \gamma$ coordinate system defines an orientation $\mathrm{C}$-space which may be used in finding an optimal trajectory of $(\alpha, \beta)$ along the CC-path.

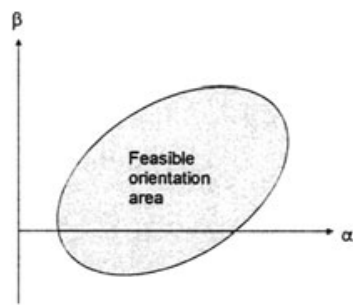

Figure 7 Orientation C-space Construction

\section{IMPLEMENTATION ISSUES}

The potential benefits of the C-space approach can only be realized through a reliable and efficient implementation scheme. For a successful implementation, we need a compact scheme for representing the C-space elements, an efficient method for computing the C-space elements, and algorithms for generating tool-paths in C-space. In this section, the above implementation issues will be examined for the design CL-surface.

The design CL-surface $\left(\mathrm{S}_{\mathrm{D}}\right)$ is the most important C-space element because most of the geometric information needed for tool-path generation is contained in it. In looking for a suitable representation scheme for $S_{D}$, the following items have to be considered:

(1) The CL-surface $\left(S_{D}\right)$ can be represented in nonparametric surface[9] form: $z=f(x, y)$.

(2) The CL-surface can be obtained by computing the inverse tool-offset (ITO) surface.

(3) It is required to trace the sharp edges of $S_{D}$ (for balanced cutting-load).

(4) It is required to compute curvatures of $S_{D}$ (for balanced cutting-load).

(5) It is required to extract some machining features from $S_{D}$ (for tool-path planning).

(6) It is required to intersect $S_{D}$ with planes (for tool-path generation). 


\subsection{Representation and Computation of C-space Elements}

It turns out that the above requirements are quite effectively handled by the Z-map model[4] which is a special form of discrete non-parametric surface model. It is a 2D-array of (real) numbers in which the z-values of the surface sampled at the regular grid-points are stored. With the Z-map representation, the ITO-surface may be easily obtained from the inverse offset method (Minkowski sum of the surface and the inverse cutter) by employing one of the cutting simulation algorithms $[12,7]$.

Presented in the following is an example of CL-surface implementation based on an edge-extended Z-map model which we call the EZ-map model. As shown in Figure 8, a fixed number of $z$-values are adaptively sampled, if necessary, from the grid-edges that are located in the near-vertical (or sharp-corner) regions. As a result, the grid-resolution at the near-vertical regions can be selectively increased from the z-map grid interval to the e-map grid interval.

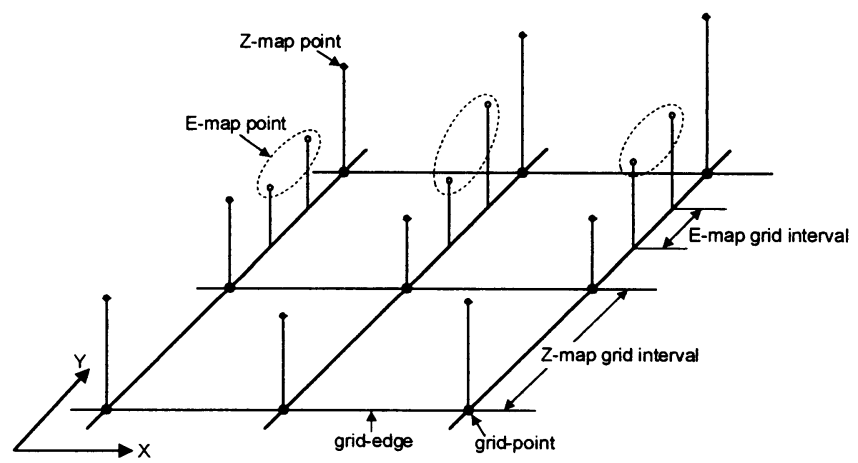

Figure 8 Edge-extended Z-map (EZ-map)

Shown in Figure 9 is a CAD model for the design surface of a stamping die for the fuel tank of a passenger car, and its master EZ-map model is shown in Figure 10. In the example case, the EZ-map model shown in Figure 10 is defined as follows: 1) Size of the Z-map domain is $1,100 \mathrm{~mm}$ by 730 $\mathrm{mm}$ (in $\mathrm{x}$ - and $\mathrm{y}$-directions); 2) z-map grid interval $=1.0 \mathrm{~mm} ; 3$ ) e-map grid interval $=0.1 \mathrm{~mm}$; 4) Memory size $=7.07$ Mbytes. The procedure for generating an EZ-map model from a CAD is called z-map sampling or (virtual) digitizing. Running on a SGI workstation (Indigo2 XZ), it takes about 50 minutes to digitize the surface and store the data (over 1 million points) in the EZ-map.

Shown in Figure 11 is the design CL-surface for a ball-endmill of $30 \mathrm{~mm}$ in diameter. It takes about 34 minutes to generate it from the master model of Figure 8 and to store in the same EZ-map form (using the algorithm of 
Reference 7). Concave type sharp-edges (or pencil curves) in the CL-surface are displayed in Figure 12, which takes about 4 minutes to compute (using the method of Reference 18). Even though the illustration does not represent a full implementation of the $\mathrm{C}$-space method, it does demonstrate that the $\mathrm{C}$ space method can be implemented using the EZ-map representation.
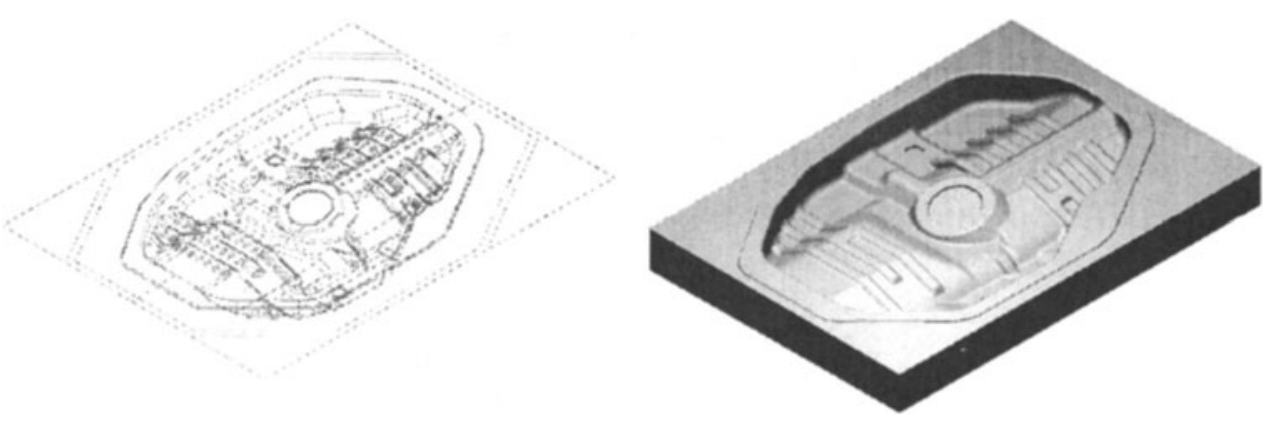

Figure 9 Design Surface (Fuel-Tank Die)

Figure 10 Master Z-map Model of the Design Surface

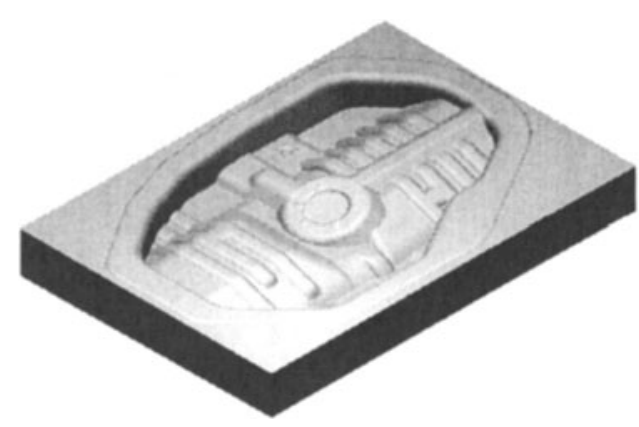

Figure 11 Design CL-Surface $\left(\mathrm{S}_{\mathrm{D}}\right)$

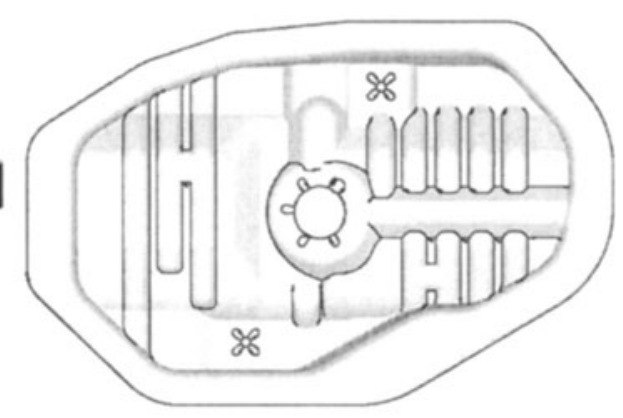

Figure 12 Concave type Sharpedges in the CL-Surface

\section{CONCLUSIONS AND FUTURE RESEARCH DIRECTIONS}

The main objective of the paper is to present a new approach to sculptured surface machining (SSM) because the existing approaches are not suitable for handling the SSM requirements. It is postulated that the proposed C-space approach could meet all the SSM requirements. The main characteristics of the C-space approach include: 1) gouge-free and collisionfree machining, 2) balanced cutting-load (by relief cutting and adjusting 
feeds), 3) generation of smooth tool-paths, and 4) tool-path planning based on machining features. However, the hard part of the C-space approach is finding an efficient implementation scheme. An extended Z-map called EZmap is introduced as a candidate for representing the $\mathrm{C}$-space elements $\left(\mathrm{S}_{\mathrm{S}}\right.$, $\mathrm{S}_{\mathrm{D}}, \mathrm{V}_{\mathrm{F}}, \mathrm{V}_{\mathrm{M}}$ and $\mathrm{V}_{\mathrm{G}}$ ), and an illustrative example for a stamping-die of an automotive part is presented. At least for the similar type of dies, the EZmap seems to have passed a preliminary test, in terms of its memory requirement and computation time. However, the proposed C-space approach has yet to go through rigorous testing as well as theoretical analyses. As for the future research directions, one may think of the theoretical aspects of the C-space approach, implementation issues, and applications.

First of all, theoretical research is needed in such topics as: 1) mathematical foundation for the $\mathrm{C}$-space approach to multi-axis NC machining, 2) fundamental properties (or features) of the $\mathrm{C}$-space method, 3) basic theorems, 4) bounding of errors introduced at discretization. The research topics related to the implementation issues include: 1) discrete representation schemes for the C-space elements, 2) basic algorithms for the discrete models, and 3) computational geometric issues. Finally, there are a number of application areas that deserve further research efforts: 1) adaptive feed control based on the C-space information, 2) C-space based featureextraction for die-cavity machining, 3) C-space based CAPP for die-cavity machining, and 4) optimization of tool-paths and cutting conditions utilizing the $\mathrm{C}$-space information, etc.

\section{REFERENCES}

1. Bobrow, J E NC machine tool path generation from CSG part representations Computer-Aided Design, Vol 17, No 2, 1985, pp.69-76

2. Choi, $\mathrm{B} \mathrm{K}$ et al Compound surface modeling and machining Computer Aided Design, Vol 20, No 3, 1988, pp.127-136

3. Choi, B.K. and Jun, C.S. Ball-end cutter interference avoidance in NC machining of sculptured surfaces, Computer-Aided Design, Vol 21, No 6, 1989, pp. 371-378.

4. Choi, B K, Surface Modeling for CAD/CAM, Elsevier, 1991

5. Choi, B K et al Unified CAM-system architecture for die and mold manufacturing Computer Aided Design, Vol 26, No 3, 1994, pp.235-243

6. Choi, B K, Kim, B H and Kim, D H Feature extraction for CAPP of die-cavity machining, presented at the IFIP WG5.2 Workshop on Geometric Modeling in CAD, May 1996, Ailie, VA.

7. Chung, Y C and Choi, B K Non-parametric modeling of cutter swept surfaces for cutting simulation Trans. Soc. CAD/CAM Engr., Seoul, Korea, Vol 1, No 1, 1996, pp.45-55 (in Korean) 
8. Duncan, J P and Mair, S G, Sculptured Surfaces in Engineering and Medicine, Cambridge University Press, 1983

9. Farin, G, Curves and Surfaces for CAGD, Academic Press, 1993

10. Faux, I D and Pratt, M J, Computational Geometry for Design and Manufacture, Ellis Horwood, 1981

11. Jensen, C G and Anderson, D C Accurate tool placement and orientation for finish surface machining Concurrent Engineering, PED-Vol 59, ASME, 1992, pp.127-145

12. Jerard, R B, Drysdale, R L and Hauck, K Geometric simulation of numerically controlled machining Proc. of ASME Conf. on Computers in Industry, ASME, 1988, pp.129-136

13. Loney, G C and Ozsoy, T M NC machining of free form surfaces Computer Aided Design, Vol 19, No 2, 1987, pp.85-89

14. Lozano-Perez, $T$ Automatic planning of manipulator transfer movements, IEEE Trans. Sys. Man, Cyb., Vol 11, No 10, 1981, pp.681-689

15. Lozano-Perez, $T$ A simple motion planning algorithm for general robot manipulators, IEEE Jr of Robotics and Automation, Vol 3, No 3, 1987, pp.224238

16. Menon, $\mathrm{J} P$ and Robinson, $\mathrm{D} M$ Advanced $\mathrm{NC}$ verification via massively parallel raycasting Manufacturing Review, Vol 6, No 2, 1993, pp.141-154

17. Murray, R M, Li, Z and Sastry, S S, A Mathematical Introduction to Robotic Manipulation, CRC Press, 1994

18. Park, J W, Kim, B H and Choi, B K Pencil curve tracing via virtual digitizing Technical Report, KAIST IE CAM Lab., 1996

19. Saito, $\mathrm{T}$ and Takahashi, T NC machining with G-buffer method, Computer Graphics (Proc. of SIGGRAPH), Vol 25, No 4, 1991, pp.207-216

20. Choi, B K, Kim, D H and Jerard, R B C-space approach to tool-path generation for die and mould machining Computer Aided Design, 1997, to be published

21. S.J. Parry-Barwick and A. Bowyer Minkowski sums of set-theoretic models (Proc. of CSG94), 1994, pp.101-116) 